\title{
КЛИНАМЕН КАК ПОНЯТИЕ И ВАЖНОЕ ДОПОЛНЕНИЕ В ДИАЛЕКТИКЕ НЕОБХОДИМОСТИ И СЛУЧАЙНОСТИ
}

\section{CLINAMEN AS A CONCEPT AND AN IMPORTANT COMPLEMENT IN THE DIALECTIC OF NECESSITY AND CHANCE \\ V. Bernatskiy \\ P. Makuhin}

Summary: If in a number of previous publications devoted to the problem of the anthropic cosmological principle, we emphasized the unity and opposition of necessity and chance, then in this one, on the contrary, we highlight a "gap», an incompleteness in the argumentation of this dialectical law. In other words, based on the material of the reflections of Epicurus and Lucretius, as well as their like-minded people up to today, we designate a «bridge» for the reverse transition from the designated principle of unity to a different understanding of the «clinamen mechanism». Drawing on the achievements of non-classical natural science, we show that the arguments about the climax of ancient philosophers contain brilliant intuitions.

Keywords: randomness and necessity, determinism, Leucippus and Democritus, Epicurus and Lucretius, German classical philosophy, dialectical materialism, microcosm physics and a systematic approach (synergetics, chaos theory).

\author{
Бернацкий Владилен Осипович \\ Д.ф.н., профессор, Омский государственный \\ технический университет \\ Bernatskiy33@rambler.ru \\ Макухин Пётр Геннадьевич \\ К.ф.н., Омский государственный технический \\ университет \\ petr_makuhin@mail.ru
}

Аннотация: Если в ряде прошлых публикаций, посвящённых проблеме антропного космологического принципа, мы делали акцент на единстве и противоположности необходимости и случайности, то в этой, напротив, выдвигаем на первый план «пробел», неполноту в аргументации этого диалектического закона. Иначе говоря, мы - на материале размышлений Эпикура и Лукреция, а также их единомышленников вплоть до сегодняшнего дня обозначаем «мостик» для обратного перехода от обозначенного принципа единства к иному пониманию «механизма clinamen». Привлекая достижения неклассического естествознания, мы показываем, что в рассуждениях о клинамене античных философов содержатся гениальные интуиции того, что, в0-первых, пространство в определённом (важном для настоящей статьи) смысле не является изотропным, оно «насыщено» микрочастицами и полями. Во-вторыхже, системные столкновения/взаимодействия результативны главным образом внутренними случайными изменениями объектов, В т.ч. и их превращениями в «своё иное».

Ключевые слова: случайность и необходимость, детерминизм, Левкипп и Демокрит, Эпикур и Лукреций, немецкая классическая философия, диалектический материализм, физика микромира и системный подход (синергетика, теория хаоса).

Но самое существенное замечание состоит в том, что теоретическая актуальность концепта «клинамен», как мы считаем, сохраняется и в настоящее время, поскольку он фиксирует одну из возможных позиций в системе координат «случайность-необходимость». В истории же философии - от античности и до сегодняшнего дня - не только природные явления, но и социальные, и относящиеся к сфере мышления, фактически рассматриваются с точки зрения того, имеет ли они место либо с необходимостью, либо случайно. В отношении же последней категории можно согласиться с констатаций современным исследователем того факта, что она «является одной из базовых, первичных для онтологии и теории познания, и она не утратила актуальности за многие столетия научного поиска» [30, с. 3]. И интересующий нас феномен, по сути, выводит к предельным основаниям философской диалектики, ведь именно из осмысления клинамена когда-то «вырос» диалектический принцип единства и противоположности необходимости и случайности. Этому вопросу мы посвятили ряд публикаций (например, [2], [3]), полемически заострённых против 
абсолютизации роли случайности при рассмотрении взаимосвязанных вопросов возникновения и Вселенной с присущей ей «тонкой настройкой» параметров, и жизни в известной нам форме, и разума. Однако, хотя объяснение клинамена как единства необходимости и случайности с акцентом на первую составляющую нам представилась уже состоявшимся, и даже довольно традиционно-тривиальным, почему-то наша мысль вновь и вновь возвращалась к этой проблеме. И потому целью настоящей статьи является обозначение «мостика» для обратного перехода от обозначенного принципа единства к иному пониманию «механизма clinamen». Ведь со времён немецкой классической философии (давшей подробный критический анализ зафиксированной этим понятием методологической позиции) концепт «клинамен» «вышел» далеко за пределы описания «демокритовского атома». Более того, как мы попытаемся обосновать, изначально термин таил в себе более широкий смысл, нежели просто «едва заметное отклонение атомов...», однако эта имплицитная идея не привлекла к себе специально оформленного внимания.

В связи с этим исходным пунктом критического - но позитивного, нацеленного на поиск «рационального зерна» - анализа в этой статье выступят соответствующие позиции тех авторов, которые сознательно отвергают единственность традиционно философского, как «парного», дополнения. В последнем обозначенные авторы подмечают, ощущают некий гносеологический «подвох» и потому трактуют случайность термином именно «клинамен». Проиллюстрируем это парой примеров. В качестве первого из них обратимся к фигуре философа, футуролога, классика научной фантастики C. Лема, который трактовал жизнь (и, соответственно, разум) в качестве побочного «продукта Космоса», при рассмотрении причин появления которого имеет смысл говорить «только о случайных связях и совпадениях» [16, с. 152] природных факторов. Особенно важно отметить, что он называл диалектический материализм «полной бессмыслицей» $[17$, с. 100]. Более подробно лемовская онтология проанализирована нами в [19], [20]; здесь же ограничимся тем, что солидаризуемся с польским и русским исследователями «Лемиана» П. Околовским и В. Язневичем, указывающими на близость философской позиции С. Лема к той, которая ещё в античности была развита некоторыми атомистами, особенно - Лукрецием [26, с. 7]. Здесь показательно название монографии (с основными положениями которой читатель может познакомиться в [28]) П. Околовского «Материя и ценности. Неолукрецианизм Станислава Лема» (2010 г.). Вторым примером возьмём отечественного философа М.И. Ненашева, который в рамках дискуссии со своим соавтором, А.Ю. Внутских (а наша, если так будет позволено выразиться, полемика с их полемикой представлена в [4]), по теме антропного космологического принципа таким образом оценивает возникновение «человека раз- умного». Оно «не является необходимым и уж тем более неизбежным, оно случайно» [8, с. 45], причём последнее понятие трактовалось им «не как дополнение или проявление необходимости, но в смысле клинамен» [8, с. 6465]. Мы не можем счесть эту позицию убедительной, но в то же время признаем, что интересующее нас в этой статье «нечто» здесь ухвачено. Несомненно, что для экспликации такового «нечто» необходима реконструкция «мысленных ходов» классических философов по поводу клинамена. Начав её, по выражению римлян, ab ovo, укажем на амбивалентность античной атомистической мысли в отношении оценки онтологического статуса случайности. C одной стороны, присущий взглядам Левкиппа и Демокрита механистический детерминизм даёт основание для следующей оценки, данной видным советским мыслителем Ю.И. Семёновым. Создатели атомизма сознательно поставили задачу постигнуть такую форму «объективной предопределённости», как «причинно-следственная связь», которая «всегда носит не случайный, а необходимый характер» [31, с. 294]. Проиллюстрируем это лаконичными высказываниями указанных натурфилософов: Левкипп (в передаче Аэция) настаивал на том, что «всё происходит в силу необходимости и что необходимость есть судьба» [18, с. 213]. Аналогично и Демокрит (по свидетельству Диогена Лаэртского) утверждал, что «причина всякого возникновения - вихрь» $[11$, с. 346], оцениваемый им в качестве проявления «неизбежности». В начале «Наставлений» «смеющийся философ» категорично утверждал: «Люди сотворили себе кумир из случая как прикрытие для присущего им недомыслия» [18, с. 216]. Однако, дошедшие до нас рассуждения Левкиппа и Демокрита по поводу движения атомов дают основание для различных оценок, что, как покажем далее, послужило «ахилессовой пятой» рассматриваемого варианта детерминизма. Проиллюстрируем это противоречивыми оценками, которые можно найти уже у античных философов. Согласно Аристотелю, основатели атомизма «утверждают, что атомы движутся, потому что сшибаются и ударяются друг о друга» [18, с. 211]. Схожим со Стагиритом образом трактует демокритовские идеи и Филопон: «атомы движутся ... потому, что вследствие своей многочисленности отталкиваются друг от друга» [18, с. 236]. (Обратим внимание при этом на то, что это ставит вопрос о причине «сиибания» и «отталкивания», оставляя простор для различных предположений). Однако же, например, М.Т. Цицерон реконструирует позицию Демокрита иным, в определённом смысле противоположным образом: атомы «носятся в бесконечной пустоте, ... сталкиваясь в своем движении, они сцепляются, что и образует все то, что существует ...; и это движение ... мыслится не имеющим никакого начала» [33, с. 48]. Схожим образом трактует идеи Демокрита и Аэций: «неделимые тела имели движение бесцельное и случайное и двигались беспрерывно и весьма быстро» [23, с. 109]. 
С другой стороны, Эпикур и Тит Лукреций Кар попытались соединить признание объективной необходимости с объективной же случайностью, придав последней онтологический статус. Наперекор ранее рассмотренным атомистам, Эпикур писал, что предпочтительнее «верить басням о богах, чем покоряться судьбе, выдуманной физиками» [36, с. 319]. (Ведь указанные «басни» хотя бы порождают надежду «умилостивить богов почитанием», в то время как «судьба» содержит в себе «неумолимую неизбежность» [36, с. 319]). Эксплицируя онтологические корни случайности, основатель эпикуреизма указывал на то, что вертикальное падение атомов по причине собственного веса, являющееся имманентным свойством материи, может нарушаться их спонтанным отклонением от этой «отвесности», что и порождает «сцепления» атомов. Известные итальянские историки философии Дж. Реале, и Д. Антисери уточняют, что, согласно Эпикуру, таковое «отклонение» может произойти «в любой момент времени и в любой точке пространства» [29, с. 183]; соответственно, они характеризуют этого древнегреческого мыслителя в таких метких словах: «философ, который "мир на случае отстроил"» [29, с. 184]. Последователь последнего, Диоген из Эноанды, таким образом отвечает гипотетическому оппоненту, который на основе демокритовских идей отрицал бы «свободное движение» атомов. «Разве ты не знаешь, ... что атомам присуще и некоторое свободное движение, которого не открыл Демокрит, но обнаружил Эпикур?» [цит. по: 34, с. 57]. И уже в этом месте статьи отметим одно принципиальное отличие всех живущих до XX века от наших современников: они не знали неклассической механики с её техническими средствами экспериментов с элементарными частицами. Речь, в частности, идёт о том, что разгонное движение элементарных частиц в физических экспериментах осуществляется по тщательно отъюстированному «кругу» с выводом на неподвижную «цель». Но ведь в естественной природе нет круговых движений, что осознал ещё Платон, в «Государстве» приписавший следующие рассуждения по поводу верного способа изучения астрономии, а также пользы этого способа. Хотя звёздные «узоры» ночного неба и следует назвать «самыми прекрасными и совершенными» из природных «узоров», они сильно «уступают вещам истинным ... (двигающимся - В.Б. и П.М.) с подлинной быстротой и медленностью, в истинном количестве и всевозможных истинных формах» $[27$, с. 313]. Поскольку всё названное доступно лишь умопостижению, а не органам чувств, Аристокл «вкладывает В уста» своего учителя призыв «изучать астрономию так же, как геометрию, с применением общих положений» [27, с. 314], «оставив в стороне» непосредственное движение небесных тел. В связи с этим мы соглашаемся с американским философствующим математиком Морисом Клайном (1908-1992 гг.): «истинная астроно- мия», согласно Платону, изучает законы движения тел «по математическому небу, несовершенным изображением которого является видимое небо» [14, с. 13].

Лукреций зафиксировал эту идею предшественников, введя собственно понятие «clinamen», которое было употреблено во второй книге «О природе вещей»: «Лёгкое служит к тому первичных начал отклоненье / И не в положенный срок и на месте дотоль неизвестном» [32, с. 67]. Для понимания этого необходимо учитывать, что этот римский поэт и философ тяготение рассматривает в качестве атрибута материальных предметов: «Сколько и в слитке свинца, то и весить он столько же должен / Ибо всё книзу давить является признаком тела / Наоборот: пустота по природе своей невесома» [32, с. 36]. В плане онтологии это связано с критикой аристотелевской идеи о стремлении тел к «естественному месту»: «Тут одного берегись и не верь утверждению, Меммий / Что устремляется всё к какому-то центру вселенной» [32, с. 54]. Но для нас здесь важнее попытка именно спонтанными отклонения атомов объяснить «свободную волю» человека, в связи с чем позволим привести длинный пассаж Лукреция (по сути, представляющий собой contradictio in contrarium, т.е. «доказательство «от противного»)). «И коль не могут путем отклонения первоначала / Вызвать движений иных, разрушающих рока законы / Чтобы причина не шла за причиною испокон века / Как у созданий живых на земле не подвластная року / Как и откуда, скажи, появилась свободная воля / Что позволяет идти, куда каждого манит желанье / И допускает менять направленье не в месте известном / И не в положенный срок, а согласно ума побужденью?» [32, с. 66]. Соответственно, согласимся со специалистом в области истории этических идей античности Б.М. Никольским в том, что, согласно Эпикуру, «физический детерминизм неизбежно влечет за собой детерминизм в сфере человеческого поведения» [25, с. 250], что и стало одним из побудительных мотивов постулировать клинамен. Обобщим рассмотрение идей Эпикура и Лукреция двумя принципиальными выводами: во-первых, они, по сути, трактовали понятие «необходимость» в качестве «высокой вероятности», которая не является антитезой случайности. Чтобы подвести читателя к во-вторых, обратимся к статье «Механика и античная атомистика» видного советского философа и историка науки В.П. Визгина, где указывается, что «пустота» в трактовке обозначенной школы однородна и изотропна [7, с. 61], и этот мыслеобраз выступает «далёким «предшественником» абсолютного пространства классической механики» [7, с. 39]. Однако же мы считаем обоснованным трактовать рассуждения тех атомистов, которые принимают идею клинамена, как интуицию того, что атомы внезапно «отклоняются» потому, что движутся в реальном пространстве, «насыщеном» микрочастицами и полями, которые, соответственно, так или иначе, воздействуют на все макро- и микроструктуры, попадающие в его (пространства) конкретную точку. 
Поскольку эта статья не является специальной историко-философской работой, мы, рассмотрев генезис идеи клинамена как антитезы детерминизму Левкиппа и Демокрита, не будем подробно анализировать эволюцию этого концепта в дальнейшие эпохи, ограничившись теми её оценками, которые мы считаем наиболее глубокими. Цицерон, например, отмечает такое противоречие: если отклонение атомов совершается совершенно произвольно, беспричинно, то они лишаются «падения вниз» как постулированного Эпиркуром и Лукрецием «естественного движения всех тел, обладающих тяжестью» [33, с. 49]. Более того, если такового движения лишатся все атомы разом (т.е. все они разом отклонятся), то столкновений по-прежнему не произойдёт; а если отклонятся лишь некоторые, то «это означает, что атомы будут как бы получать заранее свое предназначение, какому падать прямо» [33, с. 49], а какому - нет. Мы видим В этом упрёке конструктивный момент, заключающийся в интуитивном схватывании диалектики случайности и необходимости. Чего, однако же, мы не можем сказать «с высоты сегодняшнего дня» о другом замечании Цицерона: «разве может быть что-нибудь более недостойным для естествоиспытателя, чем утверждать, что нечто происходит без причины?)» [33, с. 49].

Далее рассмотрим критику онтологизации клинамена со стороны представителей немецкой классической философии. Согласно ироничному замечанию И. Канта, Эпикур, «нисколько не смущаясь», апеллирует к «слепому случаю», весьма «удачно» объединившему атомы в «стройное целое». (Напомним удачную метафору итальянских авторов: «мир на случае отстроил»). Таковая, по характеристике кенигсбергского мыслителя, «несуразность» доводилось Эпикуром и Лукрецием до того, что они «приписывали происхождение всех живых существ именно этому слепому случаю и поистине выводили разум из неразумия» $[13$, с. 121]. Схожим образом и Г.В.Ф. Гегель, согласно характеристике словенского философа М. Долара, трактовал понятие клинамена «с презрением», отводя его (клинамена) приверженцам место «на стороне того, что лишено мысли» [12]. В связи с этим приведём цитату самого берлинского философа: согласно мысли обозначенных приверженцев, атомы в те или иные тела «соединяет ... не притяжение, а случай, т. е. то, что лишено мысли» [9, с. 239]. Соответственно, обозначенным в начале статьи сторонникам «позиции случайности» В деле возникновения жизни вообще (и Homo sapiens в частности) мы считаем возможным возразить, вслед за немецкими классическими философами: вы «приписываете» наше происхождение «слепому случаю», т. е. тому, «что лишено мысли». Но, в то же время, мы признаём определённую правоту тех авторов, которые осознавали, что концепт клинамен более «глубок», т.е. имеет нераскрытый до сих пор эвристический потенциал, поскольку латентно фиксирует некую проблему.
К. Маркс высоко оценивает идею клинамен как «один из наиболее глубоких выводов ... (который - Авторы) вытекает из самой сути эпикурейской философии» [22, c. 97], но в его трактовке указанная идея трансформируется следующим образом. «Это отклонение происходит не в определенном месте пространства, не в определенное время, оно не есть чувственное качество, оно есть душа атома. В пустоте различие веса исчезает, это значит: она есть не внешнее условие движения, а само для себя сущее, имманентное абсолютное движение» $[22$, с. 99]. Другими словами, «в отклонении представлена действительная душа атома, понятие абстрактной единичности» [21, с. 173]. Последняя же «может осуществить свое понятие - присущее ей определение формы, чистое для-себя-бытие, ... только путем абстрагирования от противостоящего ей наличного бытия» [21, с. 173]. Это позволяет нам согласиться с современным исследователем фиксируемой понятием «клинамен» проблематики А.В. Шляковым в том, что рассмотренный нами основатель диалектического материализма «отстаивает позицию атома как принципа», предполагающую следующее. «Ничто не может воздействовать на него (атом - Авторы) кроме внутренней причины, находящейся внутри, и клинамен также принадлежит этой внутренней причинности, а не фатуму» [35, с. 109]. Отсюда вполне очевидно, что вряд ли Эпиркур и Лукреций согласились бы с К. Марксом в таковой трактовке их важнейшей идеи.

Переходя к оценкам последней со стороны философов XX в., ограничимся тремя фигурами; упомянутый выше М. Долар утверждает, что эвристический потенциал концепта «клинамен» до сих не эксплицирован в должной мере [12]. А. Конт-Спонвиль в рамках того определения понятия «клинамен», с которого мы начали статью, отвергает не каузальность как таковую, а лишь «непрерывность сцепления причин». Иначе говоря, клинамен сам по себе отнюдь не беспричинен, поскольку порождён «атомом, который сам не рождается (и, следовательно, не нуждается в причине)» [15, с. 254]. Здесь А. Конт-Спонвиль ссылается на своего соотечественника и коллегу М. Конша, солидаризуясь с его оценкой клинамена в качестве принципа, не противоречащего принципу каузальности, поскольку клинамен вовсе «не предполагает, что всякая причина должна порождать следствие в конкретных условиях места и времени» [15, с. 254]. Соответственно, клинамен в такой трактовке отнюдь не является свидетельством автономности случайности, и тем более её онтологического примата. Ещё один французский философ, создатель «материализма встречи» Л.П. Альтюссер, высоко оценивает роль клинамена, порождающего «событие встречи» атомов. Именно последняя порождает сам мир и, в частности, такое его свойство, как необходимость [37]. Которая, заметим, «не тянет» за собой случайность. При таком подходе понятие «клинамен» - как это ни покажется парадоксальным - фиксирует онтологический примат не случайно- 
сти, а необходимости по отношению к миру.

И, наконец, завершим ретроспективу осмысления дилеммы «случайность-необходимость» рассмотрением клинамена в свете двух фундаментальных достижений науки XX в. Во-первых, это физика микромира, в связи с чем приведём констатацию видным советским физиком, президентом АН СССР (1945-1951 гг.) С.И. Вавиловым «поразительного совпадения» «принципиального содержания» идеи клинамена с «соотношением неопределенности» современной физики» [6, с. 33]. Поясняя это, скажем, что речь о «принципе неопределенности» великого философствующего естествоиспытателя В. К. Гейзенберга, согласно которому результат измерения сопряжённых параметров (например, импульса и координат электрона, энергия и время, и т.п.) имеет предел точности, поскольку произведение «неопределённостей», возникающих в указанном процессе, «не может быть меньше постоянной Планка (делённой на массу частицы, о которой в данном случае шла речь)» [10, с. 17]. Однако же - если говорить строго - в отношении «соотношения неточностей» надо отойти от первичной эйфории по поводу «научно-физического подтверждения» идеи клинамен, хотя она (эйфории) и весьма заманчива. Ведь перед нами и не необходимость, и не случайность, и не их диалектика, а феномен особых условий измерения некоторых параметров элементарных частиц сконструированными приборами, искусственное измерение.

Bo-вторых, это развитый австрийским биологом Л.фон Берталанфи, отечественным энциклопедистом А.А. Богдановым, его американским коллегой Г. Саймоном и другими мыслителями первой половины XX в. «системный подход» (близкими к этому понятию являются «общая теория систем», «системные исследования», «системный анализ» и т.д.), представляющий собой философско-методологическое течение, ориентирующееся на «раскрытие целостности объекта и обеспечивающих её механизмов, на выявление многообразных типов связей сложного объекта и сведение их в единую теоретическую картину» [5, с. 559]. Применяя это к рассмотрению клинамена, скажем, что надо вести речь не об единичных столкновениях/взаимодействиях, а о системных. Этапом развития рассматриваемого подхода является подход синергетический, представляющий собой «совокупность принципов, основой которой является рассмотрение объектов как самоорганизующихся систем» [24, с. 183]. В свою очередь, в рамках того междисциплинарного синтеза, который и «ответственен» за синергетический подход, нас наиболее интересует тот раздел теории динамических систем, который получил известность как «теория хаоса». Британский физик Д. Аль-Халили формулирует кредо последней в таких словах: «порядок и детерминизм могут породить то, что на поверку оказывается случайностью» [1, с. 216]. Как мы показали, одними из первых это осознали именно Эпикур и Лукреций; соответственно, можно удивляться их прозорливости. Завершая статью, мы считаем принципиально важным повторить: всё рассмотренное вовсе не означает отказа от тезиса о необходимости диалектического дополнения случайности необходимостью. Однако же классический диалектический подход «с высоты сегодняшнего дня» должен быть дополнен представлением о системности сложных объектов: и природных, и социально-общественных, включая и человека. В свете этого становится явным следующее: исследуемое в нашей статье понятие имплицитно содержит в себе интуицию того, что все взаимодействия результативны не только бесконечностью движения, но и внутренними случайными изменениями объектов, в т.ч. и их превращениями в «своё иное». (В качестве наглядной иллюстрации чего укажем на факт реальной жизни организмов с их наследственностью и индивидуальностью). И потому сформулируем вывод о том, что всё же клинамен, во-первых, самостоятельный онтологический феномен, являющий себя трудно фиксируемыми внешними изменениями. Во-вторых, - это не просто необходимость присутствия случайности в процессе существования и качественного изменения «вещей», но и предопределенность внешнего воздействия на активирование случайности.

ЛИТЕРАТУРА

1. Аль-Халили Д. Парадокс. Девять великих загадок физики. СПб.: Питер, 2018. 288 с.

2. Бернацкий В.О., Макухин П.Г. Антропный космологический принцип в свете неразрывности «необходимости и случайности» // Современные исследования социальных проблем. 2016. № 4-3(28). С. 38-51.

3. Бернацкий В.О. Макухин П.Г. Антропный космологический принцип: проблема разграничения бытия и действительности // «Вопросы современной науки»: коллективная научная монография. М.: Издательство «Интернаука», 2016. Т. 10. С. 39-58.

4. Бернацкий В.О., Макухин П.Г. 0 позитивности полемики с полемикой о природе антропного космологического принципа в монографии А.Ю. Внутских и М.И. Ненашева «Антропный принцип современной науки: содержание и философские интерпретации» // Омский научный вестник. Серия «0бщество. История. Современность». 2016. № 2. С. 31-35.

5. Блауберг И.В., Садовский В.Н., Юдин Э.Г. Системный подход // Новая философская энциклопедия: В 4 т. Т.3. М.: Мысль, 2010. С. 559-560.

6. Вавилов С.И. Физика Лукреция // Лукреций. 0 природе вещей. Т. 2. Л.: Издательство Академии Наук СССР, 1947. С. 9-38. 
7. Визгин В.П. Механика и античная атомистика // Наука в её истории: взгляд философа. М.: Издательский Дом ЯСК, 2020, 2020. С. 37-117.

8. Внутских А.Ю., Ненашев М.И. Антропный принцип современной науки: содержание и философские интерпретации: монография. Пермь: Перм. госуд. нац. исслед. ун-т, 2014. 79 C.

9. Гегель Г.В.Ф. Энциклопедия философских наук. Т. 1. Наука логики. М.: «Мысль», 1974. 452 с.

10. Гейзенберг В. Физика и философия // Физика и философия. Часть и целое. М.: Наука. Гл. ред. физ.-мат. лит., 1989. С. 3-130.

11. Диоген Лаэртский 0 жизни, учениях и изречениях знаменитых философов. 2-е изд. М.: Мысль, 1986. 571 с.

12. Долар М. Атом и пустота - от Демокрита до Лакана // Новое литературное обозрение. 2016. № 6 (130). С. 16-28.

13. Кант И. Всеобщая естественная история и теория неба // Кант И. Сочинения: В 8 т. Т. 1 / Под общ. ред. А.В. Гулыги. М.: ЧОРО, 1994. С. 113-260.

14. Клайн М. Математика. Поиск истины. М.: Мир, 1988. 295 с

15. Конт-Спонвиль А. Clinamen // Конт-Спонвиль А. Философский словарь. М.: Этерна, 2012.

16. Лем С. Антропный принцип // Лем С. Черное и белое (сборник). М.: АСТ, 2015. С. 145-153.

17. Лем С. «Весь этот философский хлам» // Лем С. Черное и белое (сборник). М.: АСТ, 2015. С. 88-112.

18. Лурье С.Я. Демокрит. Тексты. Перевод. Исследования. Л.: Ленинградское отделение издательства «Наука», 1970. 664 с.

19. Макухин П.Г. Заочная дискуссия со Станиславом Лемом: проблема объяснения антропного принципа те(ле)ологически и «цепочкой случайностей» // Контекст и рефлексия: философия о мире и человеке. 2017. Том 6. № 4 А. С. 131-149.

20. Макухин П.Г. «Ценное заблуждение». Лема о взаимодействии философии и естествознания в контексте осмысления антропного космологического принципа // Вестник развития науки и образования. 2017. № 2. С. 56-67.

21. Маркс К. Различие между натурфилософией Демокрита и натурфилософией Эпикура // Маркс К., Энгельс Ф. Сочинения. Издание 2. Том 40. М.: Издательство политической литературы, 1975. С. 147-233.

22. Маркс К. Тетради по эпикурейской философии // Маркс К., Энгельс Ф. Сочинения. Издание 2. Том 40. М.: Издательство политической литературы, 1975. C. $21-140$.

23. Материалисты Древней Греции: собрание текстов Гераклита, Демокрита и Эпикура / ред. М.А. Дынник. М.: Государственное издательство политической литературы, 1955.239 с.

24. Некрасов С.И., Некрасова Н.А. Синергетический подход // Философия науки и техники: тематический словарь справочник. Учебное пособие. Орёл: ОГУ, 2010. С. 183.

25. Никольский Б.М. Комментарии // Цицерон 0 пределах добра и зла. Парадоксы стоиков. М.: Российский государственный гуманитарный университет, 2000. С. 243-418.

26. Околовский П., Язневич В.И. Лем // Summa Lemologiae 2014. Сборник материалов о жизни и творчестве С. Лема по итогам 2014 года / Составитель: В. Борисов. Лемберг: Мимоид, 2016. С. 6-25.

27. Платон. Государство // Платон. Собрание сочинений: В 4 т. Т. 3. М.: Мысль, 1994. С. 79-420.

28. Прашкевич Г.М., Борисов В.И. Станислав Лем. [Электронный ресурс]. М.: Молодая гвардия, 2015. 368 c. URL: https://sv-scena.ru/Buki/Stanislav-Lyem.205. html (дата обращения: 17.10.1980).

29. Реале Дж., Антисери Д. Западная философия от истоков до наших дней. І. Античность. СПб.: Т00 ТК «Петрополис», 1997. 336 с.

30. Самойлова 0.А. Случайность в природе: онтологический анализ: дис. ... кандидата философских наук: 09.00 .01 [Место защиты: ФГБОУ В0 «Саратовский национальный исследовательский государственный университет имени Н.Г. Чернышевского»], 2019. 131 с.

31. Семенов Ю.И. Введение в науку философии: В 6 книгах. Книга 2. Вечные проблемы философии: от проблемы источника и природы знания и познания до проблемы императивов человеческого поведения М.: URSS, 2013. 339 c.

32. Тит Лукреций Кар. 0 природе вещей. М.: Художественная литература, 1983. 383 с.

33. Цицерон. 0 пределах блага и зла // Цицерон 0 пределах добра и зла. Парадоксы стоиков. М.: Российский государственный гуманитарный университет, 2000. C. 41-452.

34. Шакир-заде А.С. Эпикур. М.: Соцэкгиз, 1963. 223 с.

35. Шляков А.В. Клинамен. Основание номадизма // Вестник ЧелГУ. 2018. №9 (419). С. 108-113.

36. Эпикур. Письмо к Менекею // Тит Лукреций Кар. 0 природе вещей. М.: Художественная литература, 1983. С. 315-319.

37. Ямпольский М. Пригов: очерки художественного номинализма. [Электронный ресурс]. М.: Новое литературное 0бозрение, 2016. 348 c. URL: https://domknig.com/read_232629-21 (дата обращения: 17.10.1980).

( Бернацкий Владилен Осипович (Bernatskiy33@rambler.ru), Макухин Пётр Геннадьевич (petr_makuhin@mail.ru).

Журнал «Современная наука: актуальные проблемы теории и практики» 